\title{
Blended learning to enhance English writing assignments without using online tools
}

\author{
Parichart Charernwiwatthanasri \\ Prince of Songkla University, Phuket, Thailand \\ parichart.c@phuket.psu.ac.th \\ *) correspondence: parichart.c@phuket.psu.ac.th
}

\begin{abstract}
From face-to-face to online teaching an English for Reading and Writing course is challenging to provide learning strategies and assessments that fit the pedagogical style of the online environment since there are many online tools (e.g. translation machine, grammar check software, and websites) for assistance in English writing. This study aims to investigate students' learning strategies in taking an online writing assignment, with an emphasis on using authentic assessments to encourage students to avoid using online tools and plagiarism in their writing. The findings show that during online learning, students made use of online tools, and they searched for the information on the internet as an assistance in writing an assignment. However, using Blended Learning and four different types of writing tasks significantly reduces the use of online tools, and it enhances students' active participation in the assessment process. The guided instructions of each task also help students to improve their writing skills, and most of the students preferred to work in small groups to complete the activities online which enhanced interaction and the sense of an online learning community.
\end{abstract}

Keywords: blended learning; writing assignment; online tools

\section{INTRODUCTION}

As in many countries worldwide, the COVID-19 pandemic situation has posed unprecedented challenges in Thailand, which requires teachers to adapt from face-to-face to online teaching. The delivery of online lessons is served as a channel for teaching and learning interaction, especially to facilitate whole-class assignments during COVID-19 closures.

In teaching English writing online, the teachers may confront some of the challenges to find out some practical ways to help students improve their writing skills since writing in a foreign or second language is intricate, and it is a courageous experience for students whose native language is not of the same origin as the target language. Also, nowadays there are various online tools, which in this study are defined as translation machine software and grammar checker software, that can facilitate students to write English sentences and paragraphs, and also websites that allow students to take the work or ideas of other people. Machine translation are popular both inside and outside the classroom, but among the growing number of students who are using it, a small number of them know how to use machine translation as a pedagogical tool in the EFL classroom (Lee, 2020). According to the study of Lee (2020), it found that translation machine software can be useful to language learning as a teaching guide, but teachers must be aware of its limitations and provide enough guidance to students for learning benefits.

With assistance of online tools and information taken from the websites, the students may not pay attention to improve their writing skills, especially when they are taking the assignments online asynchronously without any monitoring or facilitation of teachers.

In order to manage learning and teaching English writing skills during a pandemic of COVID19, Blended Learning is a good choice that allows the students to be able to get some helps or facilitation through a variety of learning activities to enhance and improve students' writing skills. Blended Learning (BL) is defined as a combination of online learning and a face-to-face learning that 
should be a seamless, personalized integration of all components of a course (Wickham, 2014). The survey report of I. Elaine Allen, Jeff Seaman and Reichard Garnette (2007) shows that the definition of Blended Learning is that one where between 30 and 79 percent of the program content is delivered online whereas an online program is on where at least 80 percent of the course content is conducted online. Figure 1 displays the system of Blended Learning that presents the integration of a face-toface learning and online learning.

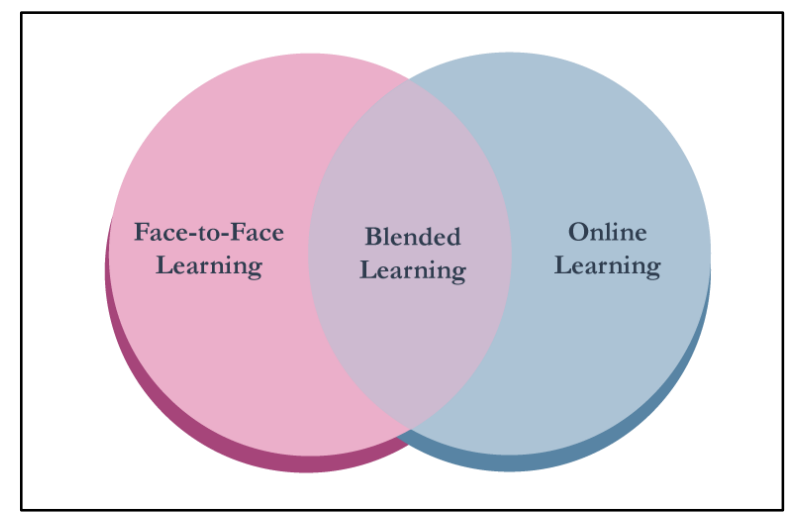

FIGURE 1. Blended Learning System

Graham (2006) states that BL systems are designed intentionally to promote learning by facilitating the combination of visual cues and educational concepts. Virtual environments acts are used to capture the attention of the learners while having augment interactions between others. According to Bryan and Volchenko (2016), BL is one of efficient method being widely used that integrates controlled and guided experiences by the instructor in the form of a face-to-face communication with electronic environments and resources. Also, Bryan and Volchenko (2016) pointed out that BL can be adopted and used for the higher education courses in Russia, especially the foreign language training.

There are several studies show the effectiveness of BL in teaching language, like English. The first one is the study of Oweis (2018) revealing that using Blended Learning method on students' achievement and motivation to learn English in Jordan was effective because the students who studied through BL performed better, and they had higher motivation than the students who were taught with traditional methods. The second one is the study of Klimova (2017), which found that the students were satisfied with the BL strategy although the use of BL approach was not much effective in teaching Business English.

With the benefits of BL; therefore, the present study aims 1) to investigate students' learning strategies in taking an online writing assignment, and 2) to investigate if learning English writing via BL reduces the use of online tools and enhances their writing skills.

\section{METHODS}

In this study, the subjects were 62 students who were taking an English for Reading and Writing course as a compulsory course in the first semester of the 2020 academic year at the Faculty of International Studies, Prince of Songkla University Phuket Campus. Research instruments in this study consisted of teaching materials of four units using a commercial coursebook titled Q: Skills for Success Reading and Writing, Level A2, 2rd edition (McVeigh and Bixby, 2015), four writing assignments, the questionnaire and a group interview. The steps of data collection were described as follows.

1. The study was conducted over a period of 15 weeks: a total of 15 class periods of 100 minutes using BL with the combination of $73.33 \%$ of online learning via the platform Zoom, and asynchronous learning materials posted on the LMS (Learning Management System), and $26.66 \%$ of a face-to-face learning in traditional classroom. Examples of BL activities employed during a semester consisted of 1) small group 
discussion online, 2) class discussion, 3) discussion board, 4) writing tutor, and 5) flipped classroom. The management of teaching and learning over a period of 15 weeks is displayed in Figure 2 below.

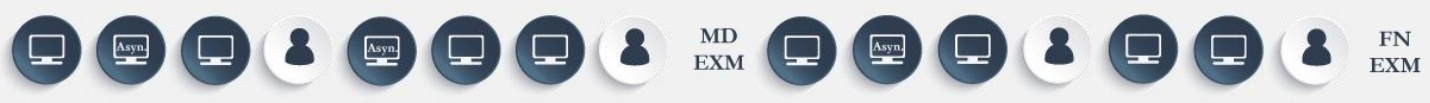

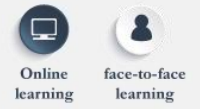

FIGURE 2. Teaching and Learning Management over a Period of 15 Weeks

The main materials were studied online synchronously, and some lessons of reading skills were learned asynchronously. All materials were posted on the LMS available at https://lms2.psu.ac.th, which allowed students to study autonomously. After each unit, the recorded videos of the lessons were posted on the LMS for students to review the lessons. See the example of the materials posted on the LMS as illustrated in Figure 3.

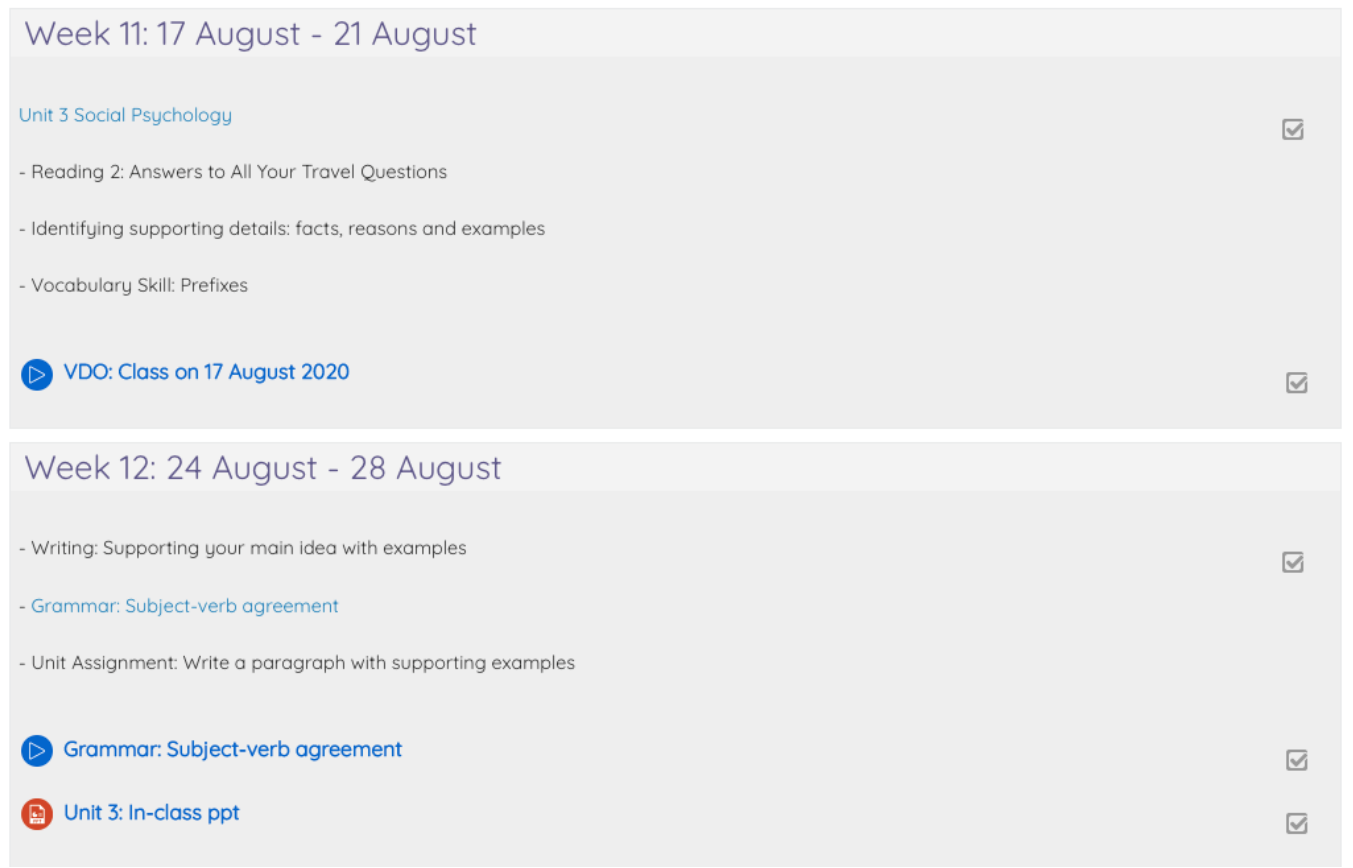

FIGURE 3. Examples of materials posted on the LMS

The students were asked to meet up with the teacher (face-to-face learning) in order to give realtime feedback and correction of the writing assignments.

2. Writing assignments were administered to the students after they have finished study each unit. The writing assignments were designed based on the contents of each unit adapted from Q: Skills for Success Reading and Writing A2. In each writing assignment, the students were asked to write a paragraph with guided instructions. Authentic topics that students are familiar in their daily life were provided. Each task has multiple choices that allowed students to choose based on their interest. The students were asked to submit each writing assignment on the LMS. See the details of four assignments in Table 1. 
TABLE 1. Details of Writing Assignments

\begin{tabular}{|c|c|}
\hline & Guided Instructions \\
\hline Writing assignment 1 & $\begin{array}{l}\text { 1. Write a five-sentence descriptive paragraph. Choose one of the trends below } \\
\text { and answer the question. } \\
\begin{array}{llll}\text { a. Tik Tok } & \text { b. Kerry } & \text { c. Fitness } \quad \text { d. Netflix }\end{array} \\
\begin{array}{l}\text { 2. In your writing, use the Present Continuous Tense and choose two words } \\
\text { below. } \\
\text { reviewers recommend influence purchase }\end{array}\end{array}$ \\
\hline Writing assignment 2 & $\begin{array}{l}\text { 1. Choose one of businesses below, and write a proposal for a new business (a } \\
\text { descriptive paragraph of } 5-7 \text { sentences). In your proposal, you will choose the } \\
\text { colors for the business and explain why you chose these colors. } \\
\text { a coffee shop at PSU a hotel at PSU a restaurant at PSU } \\
\text { 2. Use the Simple Future Tense. } \\
\text { 3. Use the vocabulary from the unit ( } 3-5 \text { words). }\end{array}$ \\
\hline Writing assignment 3 & $\begin{array}{l}\text { 1. Discuss in a group of 3-4 students about manners of one country. } \\
\text { 2. Write a descriptive paragraph ( } 5-7 \text { sentences) to answer the questions below: } \\
\text { - What do you know about manners in (name of the country)? - - - What tips } \\
\text { do you have about being polite in that country? } \\
\text { 3. Use the phrases 'for example' and 'for instance' to introduce examples. } \\
\text { 4. Use the Present Simple Tense in your writing to tell facts, truth or habits. }\end{array}$ \\
\hline Writing assignment 4 & $\begin{array}{l}\text { 1. Work in a group of } 3 \text { students. } \\
\text { 2. Write an opinion paragraph ( } 7-10 \text { sentences) on one of the given topics: } \\
\text { - an online learning } \\
\text { (Is an online learning effective?) } \\
\text { - an international program at FIS } \\
\text { (Is an international program at FIS successful?) } \\
\text { - life during COVID-19 } \\
\text { (Is life during COVID-19 stressful?) }\end{array}$ \\
\hline
\end{tabular}

For the rubric of writing assignments, students were graded on: content ( 3 points) - appropriate vocabulary, verb tenses ( 3 points) - used correctly, sentence structure ( 3 points) - subject and verb; appropriate conjunctions, grammar accuracy, punctuation \& spelling ( 3 points), and following of the instructions ( 3 points). The scores of each assignment will be calculated to $5 \%$.

3. After the first writing assignment, the students were asked to do the questionnaire on making use of the internet and online tools.

4. At the end of the semester, the students were asked to reflect teaching and learning management over a semester in a group interview.

The data in this study were analyzed using the following methods.

1. To response to the first objective of the study, the responses of the students to the questionnaire were calculated for the percentage of the use of each online tool which was used to interpret students' learning strategies in taking an online writing assignment.

2. To response to the second objective of the study, the scores on writing assignments were compared, and the observation of the researcher was used to determine the reduction of the use of online tools and plagiarism in their writing.

3. The reflection of students to teaching and learning management were brought out to determine their preference.

\section{RESULTS AND DISCUSSION}

\section{The use of online tools in writing English paragraphs}

The first objective of the study put forward for investigation students' learning strategies in taking an online writing assignment. The findings show that while doing writing assignment, the overwhelming majority of the students make use of the internet and online tools in writing English sentences and/or paragraphs. Based on the data gathered from the questionnaire, it reveals that $71 \%$ of the students made use of the internet by searching for the information of the topics given on the websites to 
complete the assignments, and they copied or took some pieces of information to compose their paragraphs. To help complete the assignment, they also used some tools as illustrated in Figure 4 below.

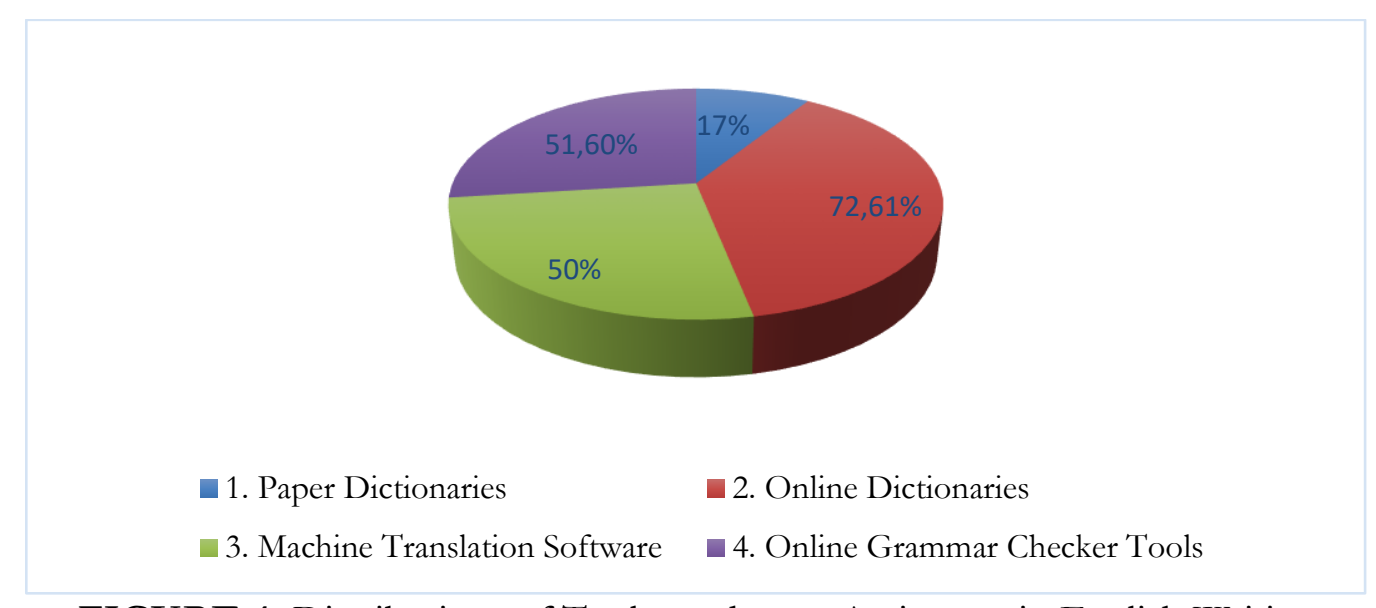

FIGURE 4. Distributions of Tools used as an Assistance in English Writing

According to Figure 4, students preferred to use online dictionaries, online grammar checker tools, machine translation software, and paper dictionaries respectively. It can be seen by the fact that half of the students consulted two different types of online tools, which were online grammar checker software and machine translation software even though these software function differently.

From the survey, it is interesting to see that online grammar checker tool named Grammarly is very popular among students. The finding shows that $85 \%$ of students used it in their paragraph writing to reduce the grammatical mistakes. Only very few of them has never used this kind of tool. The distribution of online grammar checker tools is displayed in Figure 5.

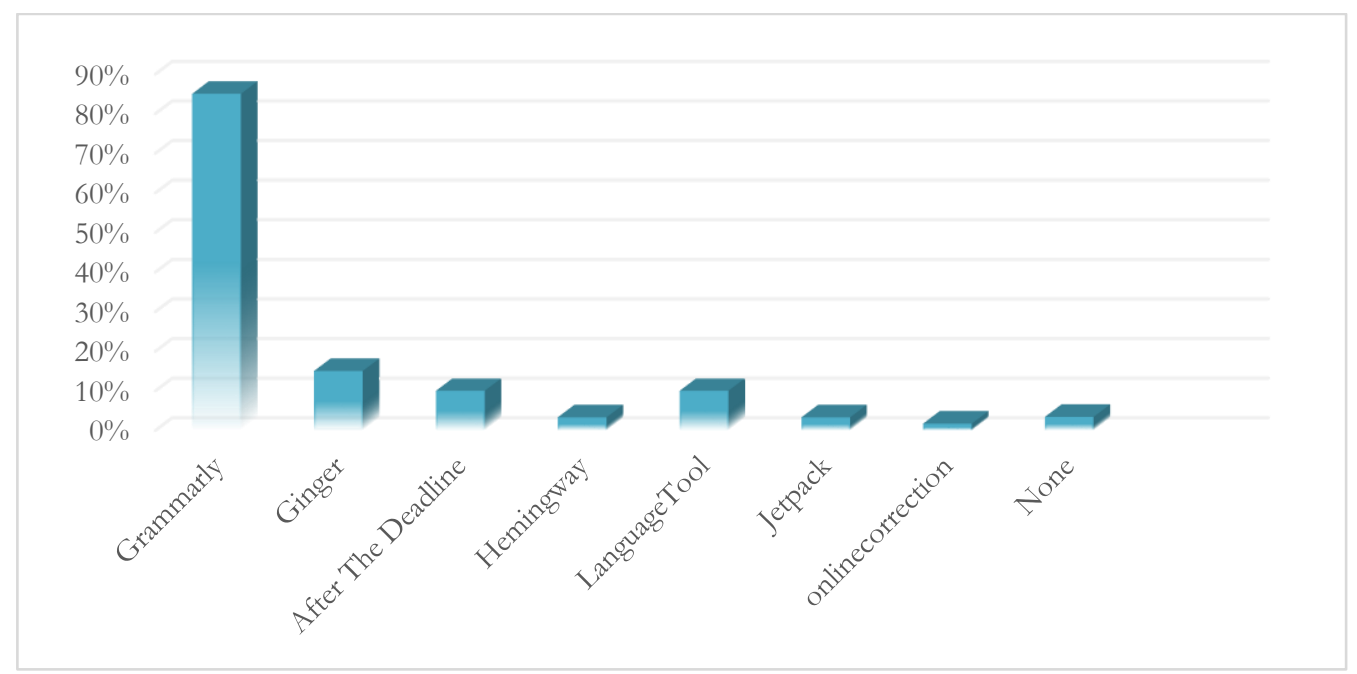

FIGURE 5. Distributions of Online Grammar Checker Tools

Figure 6 shows the distribution of translation machine software that students used while they were going writing assignment. Among various translation machine software, Google Translation is greatly preferred to use while they were completing their writing. 


\section{Parichart Charernwiwatthanasri}

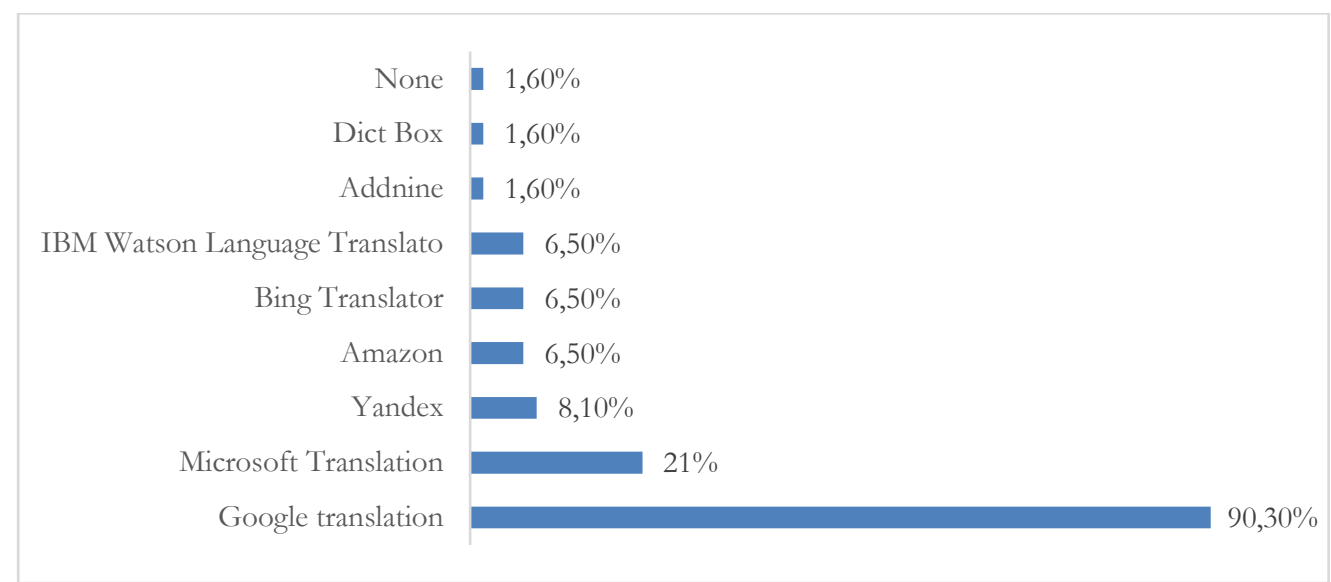

FIGURE 6. Distributions of Machine Translation Machine Software

The finding also shows that the students used translation machine software to translate their L1 writing to L2 into three different levels: word level (69.40\%), sentence level (59.70\%), and paragraph level $(24.20 \%)$.

\section{The enhancement of English writing skills}

\section{Achievement of four writing assignments}

In the study, BL was employed over 15 weeks that the course contents were delivered online, and there were face-to-face meetings. The students were asked to do four writing assignment at the end of each unit. The mean scores on four writing assignments were compared to examine if BL enhances students to be able to write English paragraphs effectively. The findings show that the mean scores of 4 writing assignments increased as shown in Figure 7.

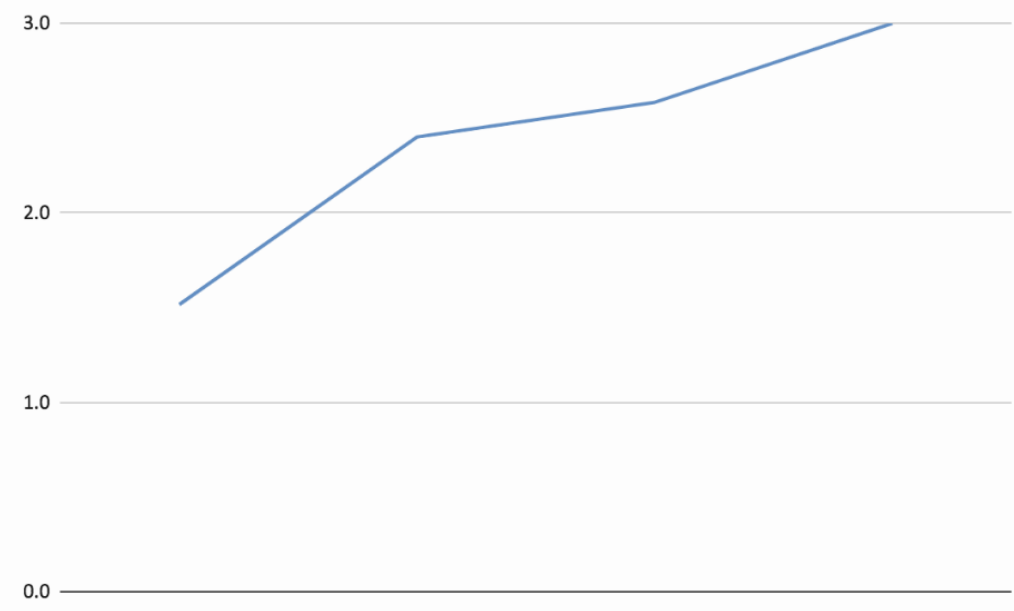

FIGURE 7. An Increase of Mean Scores of Four Writing Assignments

Although the mean scores of four writing assignments slightly increased, there was a great increase in students' English writing skills when the mean scores on the first writing assignment and the fourth writing assignment were compared. Table 2 presents a comparison of the mean scores of the two assignments.

TABLE 2. Comparison of Mean Scores of Writing Assignment 1 and 4

\begin{tabular}{ccccccc}
\hline & Mean & S.D & $\overline{\mathbf{D}}$ & S.D. & t & Sig.(1-tailed) \\
\hline Assignment 1 & 1.52 & 0.79 & \multirow{2}{*}{1.52} & \multirow{2}{*}{0.94} & \multirow{2}{*}{12.76} & ${ }^{*} 0.000$ \\
Assignment 4 & 3.04 & 0.55 & & & & $\mathrm{~N}=62$ \\
\hline
\end{tabular}

**Significant at 0.05 level 
Data in Table 2 show a significant difference in achievement of students' writing skills when the mean scores of the first writing assignment, which students did in the third week of the semester, were compared with the mean scores of the fourth writing assignment, which students did in the fifteenth week. This indicates that the students did significantly better in the fourth writing assignment, and their English writing skills improved significantly at 0.05 level.

An increase of the mean scores of writing assignments proves that BL enhances students' English writing skills. This is because an integration of a face-to-face learning and online learning allows students to study how to write and practice writing through a wide range of activities. Students can review the materials such as writing models, paragraph structures, and sentence types, many times at the time and place that is most convenient to them. With help of visual cues and controlled visual settings of computers, students were more encouraged and enhanced to supervise their learning initiatives. This is similar with the study of Graham (2006) saying that while learning having augment interactions between others via virtual environments, the learners' attention is captured. Also, when having a face-to-face discussion, it is easier to have students to negotiate and co-construct an understanding of the discussion topic. Face-to-face meetings allow teachers to give real-time feedback to the students.

\section{Reduction of the use of online tools in writing English paragraphs}

According to the results of the survey shown in Section 1, half of the students used online grammar checker software and machine translation software as an assistance in writing English paragraphs. Based on the observation of the researcher, after learning English writing with BL over a semester,

\section{Pre-Assignment (Onsite)}

if I talk about my favorite color. for me I think pink. Somebody maybe thinking about Color girls. But for me pink is color take me relax, pink take I feel comfortable When I see looking pink, I can't see pink, is color girls. I like pink because I see it I have confident. Sometime I feel not confident when everythings have pink. I changes color everything I used, because I feel not confident. But something take to do I know that favorite color is favorite color, I don't change it.

\section{Assignment 1 (Online)}

I believe the reason why Netflix is becoming widespread is because of the variety of shows it provides and its credibility. The more genre of shows Netflix has, the more likely that people would watch and recommend those shows, influencing more and more people in the process. Unlike Netflix, some streaming platforms only provide audiences with shows they made by themselves. Netflix is also known to be the best streaming platforms right now, because streaming has always been Netflix's selling point, unlike YouTube or Amazon. In conclusion, I believe Netflix is doing very well because it is diverse and convenient.

\section{Assignment 4 (Online)}

In my opinion, online learning is not good. Firstly, the learning environment is very important. If my brother make a loud noise while studying, it make me unable to concentrate and study online. Secondly, I must use the internet every time when I study online. If the internet is down, I can't study online at the same time. For example, when I was giving an oral presentation, suddenly the internet had a problem that made me upset. Lastly, studying online for a long time that makes me tired, and have a backache. Also, I can't concentrate on studying for a long time. For these reasons, I believe that online learning is not productive. We should go back to study in class. 
students reduced significantly the use of online tools and information taken from the website in their writing. To present the findings of the study in detail, only three writing tasks (Pre-assignment, Assignment 1 and Assignment 4) of only one student were selected in order to illustrate the reduction of the use of online tools and plagiarism in their writing. See examples below:

Based on the observation of the researcher on pre-writing assignment, which the student was asked to write a paragraph in class, and the first writing assignment, that the student was asked to write a paragraph on their own time, it was found that the student produced a lot of ungrammatical correct sentences in the pre-writing assignment while grammatical mistakes cannot be found in the first writing assignment. The comparison between the pre-writing assignment and the first writing assignment reveals that there was a totally difference of language used such as word choices, grammatical elements and capitalization in the two assignments. The student had a reflection in a group interview that she didn't use any online tools and/or dictionaries when doing the preassignment, but she used grammar checker software to help decrease grammatical errors in the first writing assignment. This student also used many words suggested by the software, and translation machine. After the treatment of BL and guided instructions in each writing assignment, the student did better in the fourth writing assignment. A small number of grammatical errors can be found, and the student used her own words in the task.

It can be seen from the observation of four writing assignments that the overwhelming majority of students have a reduction of the use of online tools in their writing. This can be explained by the fact that the students had time to more carefully write English sentences and paragraphs, and they provided more thoughtful reflections of guided instructions of each assignment. An authentic topic they chose encouraged them to have critical thinking based on real situations or their preferred topics. Also, when they worked in small groups, they were able to exchanged ideas with classmates, and they had confidence to discuss in breakout rooms on the platform Zoom with the facilitation and guidance of the teacher.

\section{CONCLUSION}

Blended Learning plays an important role in improving students' English writing skills during the COVID-19 pandemic situation through a wide range of learning activities (e.g. small group discussion, writing tutor, flipped classroom, computerized activities and face-to-face meetings). The results of the study demonstrate that the students performed gradually better in their writing assignments. The students reduced using online tools, and they put effort to writing English paragraphs without any assistance of online tools. Using authentic assessments, guided instructions of each assignment and Blended Learning activities enhance students' writing skills and encourage them to participate in the assessment process. The advantages of Blended Learning activities using computerized materials, which are attractively interesting designed allowed the students enjoy lessons that contains visual and sound features that make learning activities more fun. Also, Blended Learning activities provided the learner-computer interactions that gave the feedback immediately and encourage students to have many tries if the answers are incorrect. Blended Learning does not only provide computerized materials, but it also gives the opportunities to have face-to-face meetings that the teachers are able to reach more students to interact with individual or small groups of students and check on their progress. From the findings of the present study, it can be claimed that Blended Learning is one of effective strategies in English classes that the teachers can successfully implement to engage and benefit students during online teaching and learning in post-pandemic era.

\section{ACKNOWLEDGEMENTS}

I would like to express my sincere gratitude and appreciation to the Faculty of International Studies, Prince of Songkla University Phuket Campus for the financial support. Also, my grateful appreciation goes to Miss Napacha Prapawadee, my colleague, who encouraged and supported me to produce the present article, and Mr. Philip Galloway, who devoted his time to proofread this article. The errors are my own. 


\section{REFERENCES}

Allen I. E., Seaman J. \& Garnette R. (2007). Blended in the Extent and Promise of Blended Education in the United State. Sloan Consortium. Available at https://www.onlinelearningsurvey.com/reports/blending-in.pdf

Bryan A. \& Volchenko K.N. (2016). Blended Learning: Definition, Models, Implication for Higher Education, Bulletin of the South Ural State University series. Education Sciences", 8(2), 24-30. DOI: $10.14529 /$ ped160204 Available at https://www.researchgate.net/publication/303815166_Blended_Learning_Definition_Model s_Implications_For_Higher_Education

Graham C. R. (2006). Blended Learning systems. The Handbook of Blended Learning, San Francisco: Pfeiffer Publisher

Klimova B. (2017). Evaluation of the Blended Learning Approach in the Course of Business English-A Case Study. In: Huang TC., Lau R., Huang YM., Spaniol M., Yuen CH. (eds) Emerging Technologies for Education. SETE 2017. Lecture Notes in Computer Science, vol 10676, 326-335. Springer, Cham. https://doi.org/10.1007/978-3-319-71084-6_37

Lee S. (2020). The impact of using machine translation on EFL students' writing, Computer Assisted Language Learning, 33(3), 157-175, DOI: 10.1080/09588221.2018.1553186

Oweis T. I. (2018). Effects of Using a Blended Learning Method on Students' Achievement and Motivation to Learn English in Jordan: A Pilot Case Study, Education Research International, 1-8. https://doi.org/10.1155/2018/7425924

Wickham A. (2014). Blended Learning: where are we? Modern English Teacher, 23(3), 44-46. Available at https://www.modernenglishteacher.com/media/7083/met_july_23- 3_4547.pdf 